\title{
Evaluation of the complications of the in situ versus uterine exteriorization repair of caesarean section uterine incision
}

\author{
Eman Aly Abdelfattah*, Hisham Adel Elfazary, Hisham Mostafa Galal, \\ Salwa Mostafa Mohammed Elgyar
}

\begin{abstract}
Department of Obstetrics and Gynecology, Alexandria faculty of Medicine, El-Shatby Maternity hospital, Alexandria, Egypt
\end{abstract}

Received: 14 November 2021

Accepted: 19 February 2022

\section{*Correspondence:}

Dr. Eman Aly Abdelfattah,

E-mail: eman0eman0eman7@gmail.com

Copyright: (c) the author(s), publisher and licensee Medip Academy. This is an open-access article distributed under the terms of the Creative Commons Attribution Non-Commercial License, which permits unrestricted non-commercial use, distribution, and reproduction in any medium, provided the original work is properly cited.

\begin{abstract}
Background: caesarean section is the most performed major operation around the world. In this study we aim to compare in situ repair of caesarean section uterine incision to repair with uterine exteriorization.

Methods: The study was conducted on 200 patients at El-Shatby maternity university hospital during the period from June 2019 to June 2020 and after ethical committee approval and obtaining an informed consent. All cases were 37 weeks gestation or more with singleton fetus prepared to have caesarean section. They were randomly allocated into 2 groups each of 100 participants: group A: with exteriorization repair of the uterus, group B: with in situ repair. After history taking, examination and laboratory investigations, elective caesarean section was done under spinal anesthesia. After delivery of the fetus and placenta, the uterus was repaired either in situ or after exteriorization followed by closure of the abdomen in layers. We assessed: primary outcome: blood loss. secondary outcome: nausea or vomiting, hypotension, operative time and duration of uterine repair, tachycardia, uterine contractility and hematoma formation. Post-operative pain, febrile illness, time of ambulation, time of return of bowel function were also assessed. Data were collected and submitted to statistical analysis.

Results: In situ repair had a statistically significant decrease in intra operative nausea, vomiting and tachycardia. Exteriorization resulted in significantly shorter duration of uterine repair; unlikely duration of the whole surgery was not statistically significant. Return of intestinal sounds was statistically significant in favour of in situ repair.

Conclusions: There is no definite or absolute privilege of in-situ repair versus exteriorization.
\end{abstract}

Keywords: Caesarean section, Uterine incision, In-situ repair, Uterine exteriorization

\section{INTRODUCTION}

Caesarean section is the delivery of the fetus through a surgically created incision in anterior uterine wall. ${ }^{1}$ Closed either with uterine exteriorisation or in-situ repair with no reported significant differences in blood loss, febrile complications, surgical time and pain. Both are reasonable, depending on practitioner preference. ${ }^{2}$

Caesarean section has reported short-term complications as intra-and post-partum hemorrhage, infection and infectious complications as high fever, wound infection, endometritis and urinary tract infection. ${ }^{3-5}$ Pelvic abscess, septicemia, and septic shock, necrotizing fasciitis, and septic pelvic vein thrombophlebitis. ${ }^{6}$ Vascular thromboembolism and operative injuries are also reported. ${ }^{3}$

Long-term complications were also reported as keloids, adhesions, uterine adhesions and uterine CS defect (CSD) or "niche", scar ectopic pregnancy and placenta accreta in a subsequent pregnancy. ${ }^{7-13}$

In this study we aim at evaluating the complications of in situ repair of caesarean section uterine incision versus uterine exteriorization. 


\section{METHODS}

A clinical randomized prospective study was conducted on 200 patients during the period from June 2019 to June 2020 at El-Shatby university hospital after approval of the ethical committee of Alexandria faculty of medicine (Approval number:2018-117860) and obtaining an informed consent. Patient anonymity was preserved.

\section{Inclusion criteria included}

Elective cesarean delivery, 37 weeks gestation or more, cephalic presentation, singleton fetus included in the study.

\section{Exclusion criteria included}

Cases at risk of uterine atony and/or postpartum hemorrhage (multiple gestation, placenta accrete, placenta previa, preeclampsia, eclampsia, uterine leiomyomata, polyhydramnios), morbid obesity (BMI>35 $\mathrm{kg} / \mathrm{m}^{2}$ ), coagulopathy, cases in active labor or requiring emergency caesarean section were excluded from the study.

Participants were randomly allocated into 2 groups: Group A: 100 women with exteriorization repair of uterine incision, group B: 100 women with in situ repair of uterine incision.

After history taking, clinical and ultrasound examination, laboratory investigations (complete blood count, blood group and $\mathrm{Rh}$, coagulation studies, fasting blood sugar and complete urine analysis) were done.

Preoperative hydration using intravenous $1000 \mathrm{ml}$ Ringer's lactate solution with intravenous antibiotic (cefotaxim 2 gm) followed by spinal anesthesia.

Sterilization of surgically prepared area with povidone iodine (Betadine). Opening of the skin and the subcutaneous tissue through pfannenstiel incision and incising the fascia and the rectus sheath followed by rectus muscles separation and opening the peritoneum.

Lower segment c-shaped incision was done and the amniotic membranes were incised.

Delivery of the fetus and placenta followed by administration of intravenous uterotonics and separation of the placenta by controlled cord traction technique. Repair of the uterus by two layers closure with careful heomostasis either in situ or after exteriorization. Inspection of the uterine incision and the bladder flap. Suction of blood and amniotic fluid from para colic gutters. Sponges, laparotomy packs and instruments were counted.

Neither the visceral nor the peritoneal peritoneum was sutured, the rectus muscles were re-approximated. Rectus sheath was closed by continous non-locked absorbable sutures using vicryl 1 suture. Closure of subcutaneous tissue space only if more than $2 \mathrm{~cm}$, skin edges approximated with running subcuticular proline suture.

\section{During and after operation}

\section{Primary outcome measure}

Hemoglobin levels before caesarean section and 6 hours postoperative to estimate the effect of the technique used on blood loss.

Actual blood loss (ABL) was calculated using a modification of the gross formula: $\mathrm{ABL}=\mathrm{BV}$ [Hct (i)-Hct (f)]/ Hct (m)

Where BV the blood volume calculated using the equation (Blood volume=Body weight in $\mathrm{kgs} \times 70 \mathrm{mlkg}-1$ ), Hct (i) was the initial hematocrit, Hct (f) was final hematocrit and $\operatorname{Hct}(\mathrm{m})$ was mean hematocrit. ${ }^{14}$

\section{Secondary outcome measures}

Intra-operative nausea or vomiting, hypotensive episodes, duration of operation and duration of repairing the uterine incision (was calculated using a stopwatch), tachycardia (defined as a heart rate above 100 beats per minute), uterine contractility and additional use of oxytocics, surgical procedure (exposure and wound closure) and complications as hematoma formation.

Postoperative nausea or vomiting, postoperative pain assessed by the frequency of analgesic doses (analgesia was provided upon patient demand in the form of NSAID (declofenac sodium $75 \mathrm{mg}$ (voltaren) by IM route) and the total administrated dose was calculated.

Postoperative febrile illness, time of ambulation, time of return of bowel function calculated by assessing the time of the first gas or bowel movement and by hearing intestinal peristalsis while checking the four abdominal quadrants with a stethoscope.

Data were collected and submitted to statistical analysis.

\section{Statistical analysis of the data}

By using IBM SPSS software package version 20.0 the data were fed to the computer.

Quantitative data were described using mean and standard deviation for normally distributed data while abnormally distributed data was expressed using median, minimum and maximum. Qualitative data were described using number and percent and comparison between different groups regarding categorical variables was tested using chi-square test.

For normally distributed data, comparison between two independent population were done using independent t-test 
while more than two population were analyzed by $\mathrm{F}$ test (ANOVA).

\section{RESULTS}

The two groups had no statistical difference regarding maternal age, gestational age and maternal weight, height and BMI. Age in both groups ranged from 20 to 27 years, $\mathrm{p}=0.219$ (Table 1$)$.

Intra-operative blood loss was not statistically significant where the estimated blood loss for the exteriorization group was $456 \pm 1683 \mathrm{mls}$ compared to $505.2 \pm 172.4 \mathrm{mls}$ in the in-situ repair group $(\mathrm{p}=0.465)$ (Table 1).

Preoperative mean haemoglobin was similar in both groups: group A was 10.6 \pm 0.7 , and group B was $10.12 \pm 0.6$ $(p=0.425)$, post-operative mean haemoglobin in group $A$ $10.1 \pm 0.7$, and in group B 10.0 \pm 0.8 . No significant difference was noticed $(\mathrm{p}=0.241)$ (Table 2$)$.

Preoperative mean haematocrit $(\mathrm{Ht} \%)$ was similar in both groups; in group A was 33.4 \pm 2.1 , and in group B was $33.6 \pm 2.2$, $(\mathrm{p}=0.165)$, post-operative $\mathrm{Ht} \%$ in group A was $30.9 \pm 2.3$, and in group B was $31.0 \pm 2.5$ which was not statistically significant $(\mathrm{p}=0.211)$ (Table 3$)$.

During the operation, patients were observed for the occurrence of the intra operative nausea and vomiting. Nausea occurred in about $23 \%$ of cases in the in-situ group and in about $44 \%$ of cases of the exteriorized group, with $\mathrm{p}=0.004$ (Table 4 and Figure 1), while intra operative vomiting occurred in about $13 \%$ of cases in the in-situ group and in $40 \%$ in the exteriorized group, which was not statistically significant ( $\mathrm{p}=0.001)$ (Table 4, Figure 1$)$.

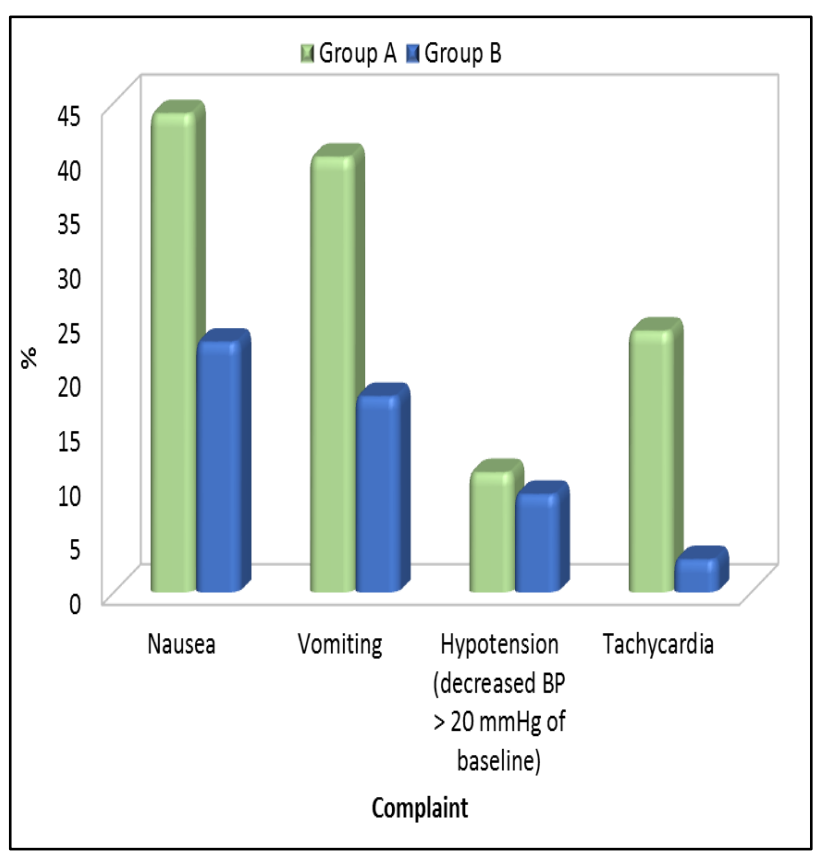

Figure 1: Comparison between the two studied groups regarding patient complaint.
Blood pressure and pulse were monitored, hypotension occurred in $11 \%$ in exteriorization group and in $9 \%$ in the in-situ group with $\mathrm{p}=0.365$ which was not statistically significant (Table 4). Tachycardia occurred in $24 \%$ in the exteriorization group and in $3 \%$ in the in-situ group, with $\mathrm{p}=0.001$, which was statistically significant. (Table 4, Figure 1).

Uterine atony occurred in 6 cases in the exteriorization group compared to 4 cases in the in-situ group which was not statistically significant $(\mathrm{p}=0.516)$ (Table 4).

Uterine hematoma occurred in 4 cases in the exteriorization group and 5 cases in the in-situ group which was not statistically significant $(\mathrm{p}=0.733)$ (Table 4).

Both groups had no significant difference as regards number of vicryl ampoules required for uterine incision repair ( $\mathrm{p}=0.634)$ (Table 5), in the in-situ group we used 1 ampoule of vicryl in 19 cases, 2 ampoules in 79 cases and 3 ampoules in 2 cases. In the exteriorized group we used 1 ampoule in 14 cases, 2 ampoules in 84 cases and 3 ampoules in 2 cases (Table 5).

We recorded the duration of uterine repair and we noticed that exteriorization of the uterus resulted in significantly shorter duration $(5.4 \pm 1.7 \mathrm{~min}$ in the exteriorization group and $7.6 \pm 1.5 \mathrm{~min}$ in the in-situ group) $\mathrm{p}=0.001$ (Table 5, Figure 2) unlikely, the duration of the whole surgery was not statistically significant, it was $27.3 \pm 5.0 \mathrm{~min}$ in exteriorization group and $25.6 \pm 31 \mathrm{~min}$ in the in-situ group $(\mathrm{p}=0.036)($ Table 5).

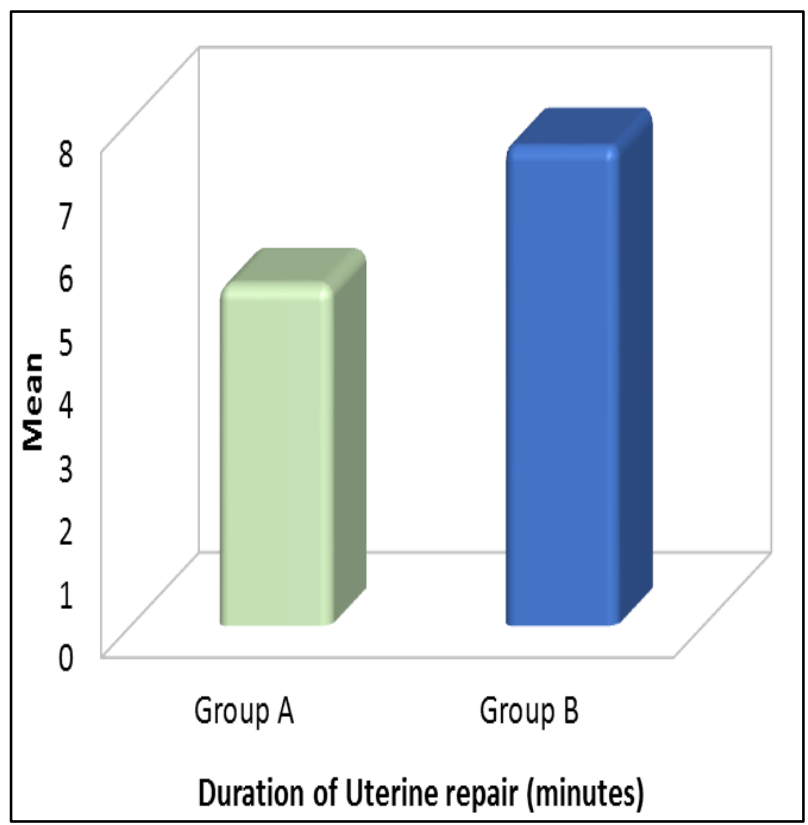

Figure 2: Comparison between the two studied groups regarding duration of uterine repair in minutes.

The need for analgesia was not significantly different between both groups $(\mathrm{p}=0.077)$ the mean dose in 
exteriorized group was $231.4 \pm 548 \mathrm{mg}$ of declofenac sodium while in in-situ group it was 221.2 \pm 46.1 (Table 5).

Nausea occurred in 46 cases in group A, and 30 cases in group B $(\mathrm{p}=0.012)$.

Vomiting occurred in 27 cases in exteriorization group, and in 20 cases in the in-situ group ( $\mathrm{p}=0.036)$.

Uterine atony occurred in 3 cases in exteriorization group, and 4 cases in the in-situ group $(\mathrm{p}=0.48)$

So, there was no statistically significant difference between the two groups regarding postoperative nausea, vomiting and uterine atony (Table 6).

Similarly, the timing of ambulation was not statistically significant; in exteriorization group, 51 cases started ambulation in less than 12 hours and 49 cases started ambulation after more than 12 hours. In the in-situ group, 47 cases started ambulation in less than 12 hours and 53 cases needed more than 12 hours to leave bed $(\mathrm{p}=0.682)$. (Table 7).

Postoperative fever as well, was not statistically different; it occurred in 5 cases only in the exteriorization group compared to 7 in the in-situ group $(\mathrm{p}=0.48)$ (Table 7).

On the other hand, return of intestinal sounds was statistically significant; the mean in the exteriorization group was $14.9 \pm 3.2$ compared to $9.7 \pm 3.3$ in the in-situ group $(\mathrm{p}=0.219)$ (Table 6, Figure 3).

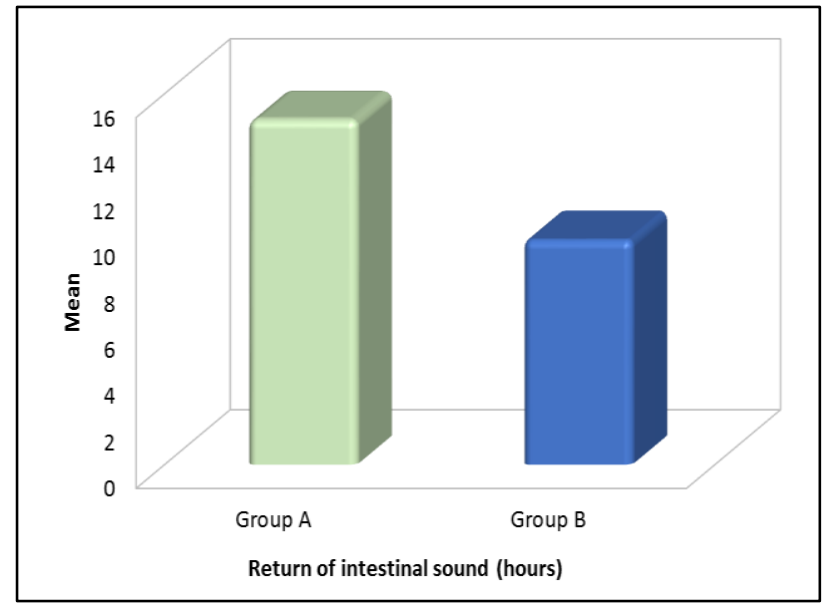

Figure 3: Return of intestinal sounds.

Table 1: Comparison between the two studied groups regarding demographic, basic data and amount of blood loss, $(\mathbf{n}=100)$.

\begin{tabular}{|c|c|c|c|c|}
\hline Variables & Group A & Group B & $\mathbf{T}$ & $\mathbf{P}$ \\
\hline \multicolumn{5}{|l|}{ Age (years) } \\
\hline Range & $20-27$ & $21-26$ & \multirow{2}{*}{0.925} & \multirow{2}{*}{0.219 N.S } \\
\hline Mean \pm SD & $23.4 \pm 2.3$ & $23.2 \pm 1.7$ & & \\
\hline \multicolumn{5}{|l|}{ Weight (kg) } \\
\hline Range & $62-91$ & $62-91$ & \multirow{2}{*}{1.36} & \multirow{2}{*}{0.115} \\
\hline Mean \pm SD & $78.1 \pm 8.8$ & $76.6 \pm 9$ & & \\
\hline \multicolumn{5}{|l|}{ Height (cm) } \\
\hline Range & $155-172$ & $154-171$ & \multirow{2}{*}{1.21} & \multirow{2}{*}{0.211} \\
\hline Mean \pm SD & $164.5 \pm 4.4$ & $164.0 \pm 4.1$ & & \\
\hline \multicolumn{5}{|l|}{ BMI $\left(\mathrm{kg} / \mathrm{m}^{2}\right)$} \\
\hline Range & $22.2-33.5$ & $21.20-33.53$ & \multirow{2}{*}{1.41} & \multirow{2}{*}{0.197} \\
\hline Mean $\pm \mathrm{SD}$ & $28.9 \pm 3.0$ & $28.5 \pm 3.2$ & & \\
\hline \multicolumn{5}{|c|}{ Amount of blood loss } \\
\hline Range & $180-850$ & $209.3-900$ & \multirow{2}{*}{0.98} & \multirow{2}{*}{0.465} \\
\hline Mean \pm SD & $456.0 \pm 168.2$ & $505.1 \pm 172.5$ & & \\
\hline
\end{tabular}

T: Student t-test, $\mathrm{p}: \mathrm{p}$ value for comparing between the two groups.

Table 2: Comparison between the two studied groups regarding pre and post-operative hemoglobin level, (n=100).

\begin{tabular}{|c|c|c|c|c|}
\hline Variables & Group A & Group B & $\mathbf{T}$ & $\mathbf{P}$ \\
\hline \multicolumn{5}{|c|}{ Hb level pre-operative (gm/dl) } \\
\hline Range & $9.55-11.93$ & $8.99-11.85$ & \multirow{2}{*}{0.89} & \multirow{2}{*}{0.425} \\
\hline Mean \pm SD & $10.6 \pm 0.7$ & $10.12 \pm 0.6$ & & \\
\hline \multicolumn{5}{|c|}{ Hb level post-operative (gm/dl) } \\
\hline Range & $9.54-12$ & $8.72-11.72$ & \multirow{2}{*}{0.92} & \multirow{2}{*}{0.241} \\
\hline Mean \pm SD & $10.1 \pm 0.7$ & $10.0 \pm 0.8$ & & \\
\hline Paired t & 0.44 & 0.68 & & \\
\hline $\mathrm{P}$ & 0.52 & 0.63 & & \\
\hline
\end{tabular}

T: Student t-test, $\mathrm{p}$ : $\mathrm{p}$ value for comparing between the two groups. 
Table 3: Comparison between the two studied groups regarding preoperative and post-operative mean hematocrit level, $(\mathbf{n}=100)$.

\begin{tabular}{|c|c|c|c|c|}
\hline Variables & Group A & Group B & $\mathbf{T}$ & $\mathbf{P}$ \\
\hline \multicolumn{5}{|c|}{ Ht\% pre-operative (gm/dl) } \\
\hline Range & $30.1-37.7$ & $30.11-37.87$ & \multirow{2}{*}{1.03} & \multirow{2}{*}{0.165} \\
\hline Mean \pm SD & $33.4 \pm 2.1$ & $33.6 \pm 2.2$ & & \\
\hline \multicolumn{5}{|c|}{ Ht \% post-operative (gm/dl) } \\
\hline Range & $25.5-35.5$ & 26.04-35.98 & \multirow{2}{*}{0.98} & \multirow{2}{*}{0.211} \\
\hline Mean \pm SD & $30.9 \pm 2.3$ & $31.0 \pm 2.5$ & & \\
\hline Paired t & 1.22 & 1.03 & & \\
\hline $\mathrm{P}$ & 0.098 & 1.03 & & \\
\hline
\end{tabular}

T: Student $\mathrm{t}$ test, $\mathrm{p}$ : $\mathrm{p}$ value for comparing between the two groups.

Table 4: Comparison between the two studied groups regarding intra-op complaints and complications, $(\mathrm{n}=100)$.

\begin{tabular}{|c|c|c|c|c|c|c|}
\hline \multirow{2}{*}{ Complaint } & \multicolumn{2}{|c|}{ Group A } & \multicolumn{2}{|c|}{ Group B } & \multirow{2}{*}{$\mathbf{X}^{2}$} & \multirow{2}{*}{$\mathbf{P}$} \\
\hline & No & $\%$ & No & $\%$ & & \\
\hline Nausea & 44 & 44 & 23 & 23 & 9.65 & $0.001 *$ \\
\hline Vomiting & 40 & 40 & 18 & 18 & 11.02 & $0.001 *$ \\
\hline $\begin{array}{l}\text { Hypotension (decreased BP>20 mmHg of } \\
\text { baseline) }\end{array}$ & 11 & 11 & 9 & 9 & 1.23 & 0.365 N.S. \\
\hline Tachycardia & 24 & 24.0 & 3 & 3.0 & 18.52 & $0.001 * *$ \\
\hline Uterine a-tony & 6 & 6 & 4 & 4 & 0.421 & 0.516 \\
\hline Hematoma formation & 4 & 4 & 5 & 5 & 0.116 & 0.733 \\
\hline
\end{tabular}

P: $p$ value for comparing between the two groups, $p<0.05$ (there is statistical significant relation).

Table 5: Comparison between the two studied groups regarding number of vicryl stitch ampoules used, dose of analgesic (voltaren) by (mg), duration of uterine repair in minutes and the duration of the whole surgery, $(\mathrm{n}=100)$.

\begin{tabular}{|c|c|c|c|c|c|c|}
\hline \multirow{2}{*}{ Groups variable } & \multicolumn{2}{|c|}{ Group A } & \multicolumn{2}{|c|}{ Group B } & \multirow{2}{*}{ Test of sig. } & \multirow{2}{*}{$\mathbf{P}$} \\
\hline & No & $\%$ & No & $\%$ & & \\
\hline \multicolumn{7}{|l|}{ Vicryl ampoule } \\
\hline One & 19 & 19.0 & 14 & 14.0 & \multirow{3}{*}{$\chi^{2}=0.911$} & \multirow{3}{*}{ 0.634 N.S. } \\
\hline Two & 79 & 79.0 & 84 & 84.0 & & \\
\hline Three & 2 & 2.0 & 2 & 2.0 & & \\
\hline \multicolumn{7}{|c|}{ Dose of analgesic (Voltaren) by (mg) } \\
\hline Range & \multicolumn{2}{|c|}{$140-310$} & \multicolumn{2}{|c|}{$150-300$} & \multirow{2}{*}{$\mathrm{t}=1.68$} & \multirow{2}{*}{ 0.077N.S. } \\
\hline Mean $\pm \mathrm{SD}$ & \multicolumn{2}{|c|}{$231.4 \pm 54.8$} & \multicolumn{2}{|c|}{$221.2 \pm 46.1$} & & \\
\hline \multicolumn{7}{|c|}{ Duration of uterine repair (minutes) } \\
\hline Range & \multicolumn{2}{|c|}{$3-8$} & \multicolumn{2}{|c|}{$5-10$} & \multirow{2}{*}{$\mathrm{t}=4.25$} & \multirow{2}{*}{$0.001 * *$} \\
\hline Mean \pm SD & \multicolumn{2}{|c|}{$5.4 \pm 1.8$} & \multicolumn{2}{|c|}{$7.6 \pm 1.5$} & & \\
\hline \multicolumn{7}{|c|}{ Duration of surgery (minutes) } \\
\hline Range & \multicolumn{2}{|c|}{$20-36$} & \multicolumn{2}{|c|}{$20-30$} & \multirow{2}{*}{2.22} & \multirow{2}{*}{$0.036 *$} \\
\hline Mean \pm SD & \multicolumn{2}{|c|}{$27.3 \pm 5.0$} & \multicolumn{2}{|c|}{$25.6 \pm 3.1$} & & \\
\hline
\end{tabular}

T: Student t-test, $\mathrm{p}: \mathrm{p}$ value for comparing between the two groups.

Table 6: Comparison between the two studied groups regarding postoperative signs and symptoms and return of intestinal sounds, $(\mathbf{n}=\mathbf{1 0 0})$.

\begin{tabular}{|c|c|c|c|c|c|c|}
\hline \multirow{2}{*}{ Signs and symptoms } & \multicolumn{2}{|c|}{ Group A } & \multicolumn{2}{|c|}{ Group B } & \multirow{2}{*}{ Test of sig. } & \multirow{2}{*}{$\mathbf{P}$} \\
\hline & No & $\%$ & No & $\%$ & & \\
\hline Nausea & 46 & 46.0 & 30 & 30.0 & $\chi^{2}=6.52$ & $0.012 *$ \\
\hline Vomiting & 27 & 27.0 & 20 & 20.0 & $\chi^{2}=2.02$ & $0.036 *$ \\
\hline Uterine a-tony & 3 & 3.0 & 4 & 4.0 & $\chi^{2}=0.52$ & 0.48 N.S \\
\hline \multicolumn{7}{|c|}{ Return of intestinal sounds (hours) } \\
\hline Range & $10-$ & & $5-1$ & & \multirow{2}{*}{$\mathrm{t}=6.21$} & \multirow{2}{*}{$0.001 * *$} \\
\hline Mean \pm SD & 14. & & 9.7 & & & \\
\hline
\end{tabular}

T: Student t-test, p: $\mathrm{p}$ value for comparing between the two groups. 
Table 7: Comparison between the two studied groups regarding the time of ambulation (hours) and postoperative fever, $(n=100)$.

\begin{tabular}{|c|c|c|c|c|c|c|}
\hline \multirow{2}{*}{ Variables } & \multicolumn{2}{|c|}{ Group A } & \multicolumn{2}{|c|}{ Group B } & \multirow{2}{*}{$\mathbf{X}^{2}$} & \multirow{2}{*}{$\mathbf{P}$} \\
\hline & No & $\%$ & No & $\%$ & & \\
\hline \multicolumn{7}{|c|}{ Ambulation duration (Hours) } \\
\hline$<12$ & 51 & 51.0 & 47 & 47.0 & \multirow{2}{*}{0.213} & \multirow{2}{*}{0.682} \\
\hline$>12$ & 49 & 49.0 & 53 & 53.0 & & \\
\hline \multicolumn{7}{|c|}{ Post-operative fever } \\
\hline Yes & 5 & 5 & 7 & 7 & \multirow{2}{*}{0.168} & \multirow{2}{*}{0.725} \\
\hline No & 95 & 95 & 93 & 93 & & \\
\hline
\end{tabular}

\section{DISCUSSION}

The ideal surgical technique for c-section continues to generate much debate in obstetric community. ${ }^{15,16}$

A study conducted by Gode et al published in 2012 reviewed medical records from 1,087 patients with caesarean section with spinal anesthesia retrospectively, 732 patients had an in situ uterine repair, and 355 patients had an exterior uterine repair.

This study and a study done by Doganay et al revealed that in situ repair of uterus is a valuable technique for repair of uterine incision. ${ }^{15,16}$ It is an easier and faster repair and offered shorter surgical time and shorter time to the first recognized bowl movement. ${ }^{16}$

On the other hand, exteriorization of the uterus is a common practice worldwide. In a meta-analysis done by Zaphratos et al published in August 2015, sixteen studies were included, about 9,736 subjects underwent exteriorization and 9,703 had in-situ uterine repair. Researchers found that exteriorization offers easier and faster repair due to better exposure of the angles decreasing the surgical time, thus decreasing intra-operative hemorrhage. They also claimed that elevation of the uterus promotes venous drainage and decreases vascular congestion there by decreasing bleeding and adverse outcomes as nausea, vomiting, pain and hemodynamic changes. ${ }^{17}$

In our study, no significant difference was found between both groups regarding blood loss matching with results found by Nasir et al in a randomized control trial published in 2011 in which 260 women underwent cesarean delivery, assigned to two groups; group A (exteriorization), group B (in-situ). Blood loss was not statistically significant $(\mathrm{p}=0.517) .^{18}$

Nasir and colleagues recruited women with primary caesarean sections as well as previous caesarean sections and this could create confounding results unlike our study where only previous one caesarean delivery were selected.

Another meta-analysis done by Zapharatos et al published in August 2015 included sixteen studies where 9.736 women underwent exteriorization and 9,703 had in-situ uterine repair. Researchers found that pooled results from six studies (908 patients) for estimated blood loss showed no statistically significant difference between the two groups. ${ }^{17}$

Exteriorization theoretically might help in decreasing blood loss by kinking uterine arteries, more effective bimanual compression, better access to uterine incision and faster suturing and haemostasis. But, relatively bloodless field during exteriorization may be a false impression as blood flows away from the operating field, unlike the pooling and obscuring of operating field that occurs with in situ repair. This was the opinion of Orji et al in their study. ${ }^{19}$

Consistent with the findings reported in the current study, Ozbay et al also found no statistically significant difference in blood loss during surgery using preoperative and postoperative haematocrit values. Their study included 338 women randomized to two groups; exteriorization group $(\mathrm{n}=171)$ and (in situ repair group) $(\mathrm{n}=167) .^{20}$

As regards intra-operative nausea and vomiting we noticed significant frequency in the exteriorization group than the in-situ group. This result matched with Shuja et al in a study which included 780 pregnant women (390 in each group). Exteriorization had been associated with more vomiting intra-operatively $(18 \%$ with in-situ repair compared to $38 \%$ with exteriorization, $\mathrm{p}<0.001) .{ }^{21}$

Zafar et al published a study in August 2016 including 170 patients divided into 2 groups; $44.7 \%$ of cases in the exteriorization had nausea compared to $22.4 \%$ in the in-situ group $(p=0.02)$. Vomiting occurred in $23.5 \%$ in exteriorization group compared to $11.8 \%$ in in-situ group $(\mathrm{p}=0.04){ }^{22}$ These findings suggest strong association between occurrence of nausea/vomiting and uterine exteriorization. This was also reported by Zapharatos et al and Bushra et al patients in the exteriorization group exhibited nausea/vomiting immediately after exteriorization and then again at time of repositioning the uterus into the abdominal cavity. ${ }^{17,23}$ 
However, these findings were not in conformity with the other literature reports which showed no statistically significant differences between exteriorization and in situ repair of uterus as regards nausea and vomiting like studies done by Gode et al and Ozbay et al. ${ }^{15,20}$

In the present study, in-situ uterine repair was associated with less intra-operative complications, nausea, vomiting, hypotension and tachycardia, all of them were statistically significant except for hypotension $(\mathrm{p}<0.05)$.

A significantly higher incidence of tachycardia and a nonsignificant increase in the incidence of hypotension, were observed among exteriorization group coinciding with repositioning of the uterus into the abdominal cavity which is a very intense stimulus explaining tachycardia.

Duration of uterine repair and surgery was significantly shorter with uterine exteriorization. Coutinho et al found a significant difference between the two techniques in an analysis which included 637 women, 312 patients had in situ uterine repair and 325 patients had exteriorized uterine repair. Time was shorter and sutures were fewer in number when the uterus was exteriorized. ${ }^{24}$

In a study by Zafar et al published in 2016; 170 women were divided into 2 groups; a significant difference was found in surgical duration being $36.38 \mathrm{~min}$ in-situ uterine repair group and $32.78 \mathrm{~min}$ in exteriorized group $(\mathrm{p}=0.0001){ }^{20}$

But in a study done by Shuja et al published in 2015 on 780 pregnant women (390 in each group); the operating time with in situ repair was less compared to exteriorization due to ease of repair and quick haemostasis, $\mathrm{p}=0.003) .{ }^{21}$

Number of vicryl ampoules used was not statistically significant but we noticed that we used a less total number of ampoules in the in-situ group than the exteriorized group, and this may become economically significant when applied to practice in hospitals. Extra ampoules were for haemostatic sutures after doing the 2 layers uterine incision closure in the exteriorized group which was rarely resorted to in the in-situ group. Concerning surgical procedure, we noticed that exposure of suture line and uterine angles were easier with uterine exteriorization, also dealing with hematomas was easier and faster but the need of doing haemostatic sutures after doing the 2 layers closure of the uterine incision was more in the exteriorized group and that's why some surgeons favored uterine exteriorization in a meta-analysis done by Zaphratos and others. ${ }^{17}$ As regards uterine atony; we did not find a difference between the two groups.

Doganay et al did a randomized control study conducted at the delivery clinic of the Zekai Tahir Burak female health education and research hospital, Ankara, Turkey, where 4925 pregnant women were assigned to in situ uterine repair (group 1) or exteriorized uterine repair (group 2). The mean operation time was $36.8 \pm 4.2$ minutes in groupland44.6 \pm 3.7 minutes in group $2(\mathrm{p}=0.001)$, intraoperative uterine atony developed in 96 cases in group 1 $(3.8 \%)$ and 226 cases in group $2(9.1 \%)$ with a $\mathrm{p}=0.001$. The study suggested that in situ uterine repair is preferred to uterine exteriorization. ${ }^{14}$

Pain control after caesarean section is a real concern for all women, in our study, pain was assessed by doses of analgesics postoperatively which was not statistically significant between both groups.

In a meta-analysis done by Zaphratos et al overall pooled results from three studies (439 patients) did not show a statistically significant difference concerning pain between the two repair techniques, but, a randomized clinical study conducted by Shuja et al found lower pain scores within the in situ uterine repair group. ${ }^{17,21}$

In our study some cases reported postoperative febrile illness but it was not statistically significant. Oreiji et al had the same result in a randomized study on 210 pregnant women. Fever occurred in $38.1 \%$ in the in-situ group compared to $26.7 \%$ in the exteriorization group $(\mathrm{p}=0.77) .{ }^{19}$

But Shuja et al found that the in-situ group had thrice the febrile morbidity compared to the exteriorized group, which was statistically significant $(\mathrm{p}=0.005) .^{21}$

In the present study, return of bowel function was significantly different between the two groups. The same results were demonstrated by Shuja et al the mean time for the first recognized bowl movement was $16.11 \pm 4.98$ hours with uterine exteriorization and $13.10 \pm 3.45$ hours with situ repair $(\mathrm{p}<0.001){ }^{21}$

Abdellah et al at a tertiary university hospital in December 2017 recruited 1028 women $>37$ weeks gestation scheduled for repeat caesarean section under spinal anesthesia, the time to the first recognized bowel movement was 12.3 hours with in situ repair versus 14.1 hours with exteriorization which was statistically significant $(\mathrm{p}=0.003) .{ }^{25}$ Also, a meta-analysis done by Zaphratos et al revealed pooled results from four studies including 3,234 women, three of them strongly recommended in situ repair with statistically significant differences reported. ${ }^{17}$

Similarly, Doganay et al found that the mean time for the first detected bowel sound was $12.03 \pm 0.44$ hours with situ repair and $15.93 \pm 0.52$ hours with exteriorization $(\mathrm{p}=0.001) .{ }^{14}$ Also, Abdellah et al in 2017 included 1028 women in a study. The time to the first recognized bowel movement was significantly lower in the in-situ group compared to the exteriorization group (12.3 hours vs 14.1 hours; $\mathrm{p}=0.003)^{25}$

\section{CONCLUSION}

There is no definite or absolute privilege of in-situ versus exteriorization, so there is no fixed protocol for caesarean section. 
In either technique some data justify a choice, so surgical situation and personal preference for a determined technique are the main guide for the choice.

\section{ACKNOWLEDGMENTS}

Author would like to thanks to doctor El-Sayed Amr for his co-operation in statistics, and to nursing staff of the operating theatre of El-Shatby hospital for their cooperation.

Funding: No funding sources

Conflict of interest: None declared

Ethical approval: The study was approved by the Institutional Ethics Committee

\section{REFERENCES}

1. Madsen K, Grønbeck L, Rifbjerg Larsen C, Østergaard J, Bergholt T, Langhoff-Roos J et al. Educational strategies in performing cesarean section. Acta Obstet Gynecol Scand. 2013;92:256-63.

2. Dahlke JD, Mendez-Figueroa H, Rouse DJ, Berghella V, Baxter JK, Chauhan SP. Evidence based surgery for caesarean delivery: an updated systematic review. Am J Obstet Gynecol. 2013;209:294-306.

3. Steer PJ. Prevention and management of post-operative caesarean section. In: Jauniaux E, Grobman W (eds). A textbook of caesarean section complications. Oxford: Oxford University Press. 2016;117-28.

4. Qin JB, Wang H, Sheng X, Xie Q, Gao S. Assisted reproductive technology and risk of adverse obstetric outcomes in dichorionic twin pregnancies: a systematic review and meta-analysis. Fertil Steril. 2016;105(5):1180-92.

5. Reddy UM, Rice MM, Grobman WA, Bailit JL, Wapner RJ, Varner MW et al. Eunice Kennedy Shriver National Institute of Child Health and Human Development Maternal-Fetal Medicine Units Network. Serious maternal complications after early preterm delivery (24-33 weeks' gestation). Am J ObstetGynecol. 2015;213:538.

6. Her M, Ray C, Blondel B, Goffinet F, Zeitlin J. The risk of pre-labor and intrapartum cesarean delivery among overweight and obese women: possible preventive actions. Am J Obstet Gynecol. 2015;212:41.

7. Jauniaux E, Jurkovic D. Long-term complications after caesarean section. In: Jauniaux E, Grobman W (eds). A textbook of caesarean section. Oxford: Oxford University Press. 2016;129-44.

8. Wang R, Mao Y, Zhang Z, Li Z, Chen J, Cen Y. Role of verapamil in preventing and treating hypertrophic scars and keloids. Int Wound J. 2016;13(4):461-8.

9. Moro F, Mavrelos D, Pateman K, Holland T, Hoo WL, Jurkovic D. Prevalence of pelvic adhesions on ultrasound examination in women with a history of cesarean section. Ultrasound Obstet Gynecol. 2015;45:223-8.
10. Stark M, Hoyme UB, Stubert B, Kieback D, Renzo GC. Post-cesarean adhesions - are they a unique entity? J Matern Fetal Neonatal Med. 2008;21(8):513-6.

11. Ofili-Yebovi D, Ben-Nagi J, Sawy E, Yazbek J, Lee $\mathrm{C}$, Gonzalez J et al. Deficient lower-segment cesarean section scars: prevalence and risk factors. Ultrasound Obstet Gynecol. 2008;31:72-7.

12. Baron J, Weintraub AY, Eshkoli T, Hershkovitz R, Sheiner E. The consequences of previous uterine scar dehiscence and cesarean delivery on subsequent births. Int J Gynaecol Obstet. 2014;126:120-2.

13. Jurkovic D, Knez J, Appiah A, Farahani L, Mavrelos D, Ross JA. Surgical treatment of cesarean scar ectopic pregnancy: efficacy and safety of ultrasoundguided suction curettage. Ultrasound Obstet Gynecol. 2016;47(4):511-7.

14. Doganay M, Tonguc EA, Var T. Effects of method of repair on surgical outcome of cesarean delivery. $\mathbf{J}$ Gynecol Obstet. 2010;111:175-8.

15. Gode F, Okyay RE, Saatli B, Ertugrul C, Guclu S, Altunyurt S. Comparison of uterine exteriorization and in situ repair during cesarean sections. Arch Gynecol Obstet. 2012;285:154.

16. Das S, Dad P, Mahli A, Biswas S. Comparative study of uterine repair during cesarean section Intraabdominal Vs exteriorization of uterus. ISORJDMS. 2015;14(1):5-8.

17. Zaphiratos V, George R, Boyd J, Habib A. Uterine exteriorization compared with in situ repair for Cesarean delivery: a systematic review and metaanalysis. Can J Anaesth 2015; 62:1209.

18. Nasir H, Imran R, Naz I, Saif N. Uterine Exteriorization compared with in-situ repair at Caesarean delivery. JRMC. 2011;15(2):110-2.

19. Orji EO, Olaleye AO, Loto OM, Ogunniyi SO. A randomised controlled trial of uterine exteriorisation and non-exteriorisation at caesarean section. Aust N Z J Obstet Gynaecol. 2008;48:570-4.

20. Ozbay K. Exteriorized versus in-situ repair of the uterine incision at caesarean delivery: a randomized controlled trial. Clin Exp Obstet Gynecol. 2011;38(2):155-8.

21. Shuja A, Akhtar S, Khan S. Comparison of intra operative and postoperative complication of intraabdominal versus extra-abdominal uterine repair at caesarean delivery. Pak Armed Forces Med J. 2015;65(2):191-4.

22. Zafar B, Shehzad F, Naseem A, Safdar A. Exteriorization or in situ; Comparison of options for uterine repair at Caesarean section delivery. Pak Armed Forces Med J. 2016;66(4):570-3.

23. Bushra Z, Farrukh S, Azra N, Aqeel S. Exteriorisation or in situ repair, comparison of options for uterine repair at Caesarean Delivery. PAFMJ. 2016;66(4):570-3.

24. Coutinho IC, Ramos Amorim MM, Katz L, Bandeira Ferraz AA. Uterine exteriorization compared with in situ repair at cesarean delivery: a randomized controlled trial. Obstet Gynecol. 2008;111:639-47. 
25. Abdellah MS, Abbas AM, Ali MK, Mahmoud A, Abdullah SA. Uterine exteriorization versus intraperitoneal repair: effect on intraoperative nausea and vomiting during repeat cesarean delivery-A randomized clinical trial. Facts Views Vis Obgyn. 2018;10(3):131-7.
Cite this article as: Abdelfattah EA, Elfazary HA, Galal HM, Elgyar SMM. Evaluation of the complications of the in situ versus uterine exteriorization repair of caesarean section uterine incision. Int J Reprod Contracept Obstet Gynecol 2022;11:726-34. 